Osteoporosis is a very common disorder, which results in an increase in fracture risk. The annual cost attributable to hip, vertebral, and wrist fractures in England and Wales is $£ 1.7$ billion. Significant mortality and morbidity are associated with osteoporotic fractures. The method that is most widely used for the diagnosis of osteoporosis is dual energy $x$-ray absorptiometry. The aim of prevention and treatment of osteoporosis is to prevent the occurrence of future fractures. Lifestyle changes should be encouraged in high risk patients. Pharmacological treatments include the bisphosphonates, hormone replacement therapy, selective oestrogen receptor modulators, calcitonin, the 1-34 fragment of parathyroid hormone, calcium and vitamin D supplements, and calcitriol.

See end of article for authors' affiliations

Correspondence to: Professor C Cooper, MRC Environmental Epidemiology Unit, Southampton General Hospital, Southampton SO16 6YD, UK;

cc@mrc.soton.ac.uk

Submitted 17 June 2002 Accepted 31 July 2002

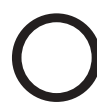
teoporosis is a skeletal disorder characterised by low bone density and microarchitectural deterioration of bony tissue. This results in an increase in fracture risk. ${ }^{1}$ The resulting fractures pose a major health problem. Hip, vertebral, and wrist fractures are most commonly associated with osteoporosis. The annual cost attributable to these fractures in England and Wales is $£ 1.7$ billion. Over $90 \%$ of the cost is due to hip fractures. ${ }^{2}$ The total cost of osteoporosis in the United States alone is estimated to be over $\$ 14$ billion per year. ${ }^{3}$ These figures are expected to increase as the proportion of elderly people in society increases.

The age specific risk of hip, vertebral, and wrist fracture among white people reveals that there is a steep increase in the incidence of fracture with age and there is a higher incidence in women than in men. By age 85 , white women have about a $3 \%$ annual incidence of hip fracture (fig 1$).{ }^{4}$ The lifetime risk of osteoporotic fracture in 50 year old British white women has been estimated at $14 \%$ for the hip, $11 \%$ for the spine, and $13 \%$ for the radius. $^{5}$ The corresponding figures in North American women are higher 17.5\%, 15.6\%, and $16 \%$ respectively. The remaining risk for any fragility fracture is about $40 \%$ in women and $13 \%$ in men. ${ }^{6}$ It is estimated that the annual incidence of hip fractures in the UK is around 60000 , that of radial fracture around 50000 , and that of clinically diagnosed vertebral fractures around $40000 .^{7}$ However, the true incidence of vertebral fractures is higher as many vertebral fractures, certainly more than two thirds and possibly as many as $85 \%$, do not come to medical attention. The World Health Organisation has defined osteoporosis as a bone mineral density (BMD) more than 2.5 SDs below the young normal mean. Osteopenia is defined as BMD between 1 and 2.5 SDs below the young normal mean. According to these criteria, the frequency of osteoporosis among 50-59 year old whites is 4\% taking into account BMD readings at the femoral neck. This figure rises to $52 \%$ in women aged 80 years or more. $^{8}$

\section{GEOGRAPHIC VARIATION}

There are significant differences in the incidence and impact of osteoporosis in different populations around the world. ${ }^{9}$ Hip fractures are much more common in whites than non-whites. Moreover, there is substantial variation within populations of a given race and gender. Age adjusted hip fracture rates are higher among residents of Scandinavia than among whites in North America or Oceania. Within European countries, hip fracture rates vary more than sevenfold from one country to another. ${ }^{10}$

\section{SECULAR TRENDS}

It is estimated that the financial and health related costs of osteoporosis will rise in future generations. 9 There are an estimated 323 million individuals aged 65 years or over at present; this number is expected to reach 1555 million by the year 2050." These demographic changes are expected to increase the number of hip fractures occurring among people 35 years and over throughout the world from 1.66 million in 1990 to 6.26 million in 2050. It is believed that currently around half of all hip fractures among elderly people in 1990 took place in Europe and North America. However, in view of the rapid ageing of the Asian population it is believed that by 2050 over half of all hip fractures will occur in Asia.

\section{MORTALITY AND MORBIDITY \\ ASSOCIATED WITH FRACTURES}

The mortality rate in an elderly person with hip fracture approaches $20 \%$. In those who survive mobility remains permanently impaired in over half of the patients. ${ }^{11}$

It appears that excess mortality also occurs after vertebral fracture and that mortality is worse for vertebral fractures that occur secondary to mild to moderate trauma than for those associated with severe trauma. Survival at five years appears to be $72 \%$ in men and $84 \%$ in women. ${ }^{12}$ However, in patients suffering vertebral fractures secondary to mild to moderate trauma only $8 \%$ of

Abbreviations: BMD, bone mineral density; DXA dual energy $x$-ray absorptiometry; HRT, hormone replacement therapy 


\section{Box 1: Epidemiology}

- Hip, vertebral, and wrist fractures are most commonly associated with osteoporosis.

- The annual cost attributable to these fractures in England and Wales is $£ 1.7$ billion.

- There is a steep increase in the incidence of fracture with age and there is a higher incidence in women than in men.

- The frequency of osteoporosis in 50-59 year old white women is $4 \%$ and $52 \%$ in women aged 80 years or more.

the deaths were thought to be due to osteoporosis. It is thought that a significant proportion of the excess mortality in patients with vertebral fractures is due to the presence of comorbid conditions.

In a cohort of white women in the United States bone density per se was shown to be inversely related to mortality. ${ }^{13}$ The women were more than 65 years old and it was shown that there was a $20 \%$ increase in mortality for each standard deviation decrease in BMD.

In the United States about $7 \%$ of patients who survive all types of fragility fractures have some degree of permanent disability and $8 \%$ require long term nursing home care. Moreover, a 50 year old white woman in the United States has a 13\% chance of experiencing fracture related functional decline after any fracture. ${ }^{14}$

It has been shown that in the United States the proportion of hip fracture patients who were discharged from hospital to nursing homes in 1990 varied from $14 \%$ in the 50-55 year old group to $55 \%$ in those over 90 years old. At the end of the first year after a hip fracture $40 \%$ of people were still unable to work independently, $60 \%$ required assistance with one essential activity of daily living-for example, dressing or bathing, and $80 \%$ were unable to perform at least one instrumental activity of daily living-for example, driving or grocery shopping. ${ }^{15}$

Multiple vertebral fractures may result in acute and chronic back pain, limitation of physical activity, and progressive kyphosis and height loss. The loss of functional capabilities might result in depression and low self esteem. Moreover pain and fear of additional fracture can cause decreased physical activity, which in turn worsens osteoporosis and therefore the risk of further fractures is increased. ${ }^{16}$

- Significant mortality and morbidity are associated with osteoporotic fractures.

\section{RISK FACTORS FOR OSTEOPOROTIC FRACTURE}

There are several risks factors that can predispose to osteoporotic fractures (table 1).

\begin{tabular}{ll} 
Table 1 Risk factors & \\
\hline Skeletal & Extraskeletal \\
\hline Reduced bone mineral density & Increasing age \\
Low body mass index & Previous falls \\
Bone architecture & Abnormal gait \\
Bone turnover & Poor coordination \\
Previous fractures & Dementia \\
\hline
\end{tabular}

\section{Bone mineral density}

It has been shown that the lower the BMD the higher the fracture risk. Bone mass can be assessed at a number of sites including the lumbar spine, the hip, the forearm, and other sites. The most commonly used technique is dual energy $x$-ray absorptiometry (DXA) at the hip and the spine.

\section{Body weight}

It has been shown in a number of studies that there is a negative correlation between low body mass index and peak bone mass. Moreover, low body mass index and weight loss are strongly associated with increased fracture risk.

\section{Cigarette smoking}

There is an inverse relationship between cigarette smoking and BMD. Many factors are believed to contribute to this including reduced body weight, an earlier menopause, and increased metabolic breakdown of exogenous oestrogen in women. In a meta-analysis, although there was no significant difference in bone density between smokers and non-smokers at age 50 , bone density in women diminished by $2 \%$ more in smokers than in non-smokers for each 10 year increase in age, with a difference between the two of $6 \%$ at age 80 years. ${ }^{17}$ Moreover, an independent effect of cigarette smoking on the risk of hip fracture has been suggested by epidemiological studies. $^{18}$

\section{Alcohol consumption}

Consumption of large quantities of alcohol may be detrimental to bone. This might be due to adverse effects on protein and calcium metabolism, mobility, gonadal function, and a toxic effect on osteoblasts. However, moderate quantities of alcohol appear to be protective against bone loss at the hip and against the risk of vertebral fracture. ${ }^{19}$

\section{Nutrition}

In a meta-analysis of many studies an association between calcium intake and bone mass was shown in premenopausal women. $^{20}$ On the other hand, the relationship between calcium intake and fracture rate is not certain.

In middle aged and elderly women a positive association has been reported between 25-hydroxyvitamin D concentration and BMD. An inverse relationship has been observed
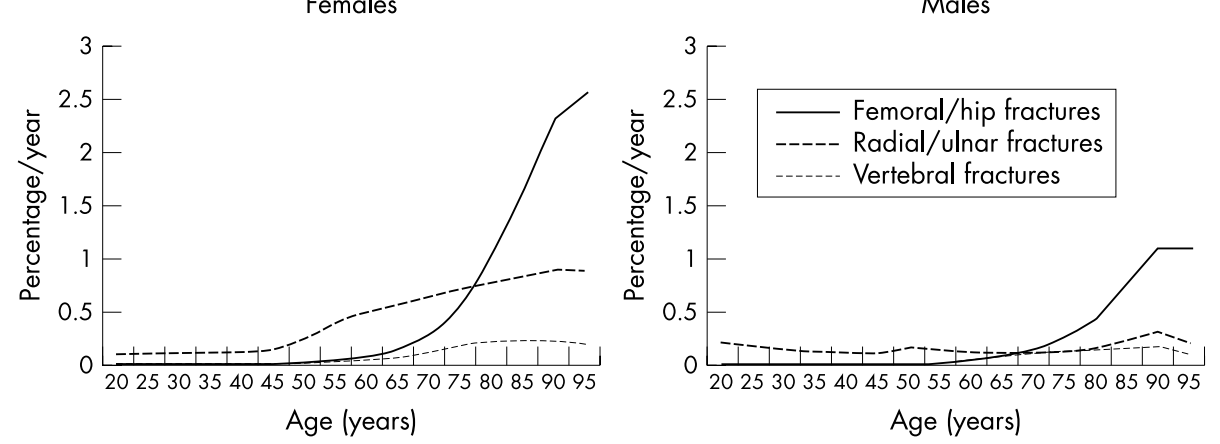
- The method that is most widely used for the diagnosis of osteoporosis is dual energy $x$-ray absorptiometry.

between serum parathyroid hormone and BMD. In addition, adequate vitamin D levels in the elderly may also improve muscle strength and reduce both the risk and consequences of falling.

\section{Physical inactivity}

It has been shown that physical loading and mechanical stress increase BMD and that certain forms of exercise may retard bone loss. ${ }^{21}$ Moreover, epidemiological studies have shown that a relationship exists between physical inactivity in the elderly and the risk of hip and vertebral fracture. Some of this effect might be due to the increased risk of falling.

\section{Sex hormone deficiency}

Primary hypogonadism is associated with low bone density in both sexes. In women with secondary amenorrhoea the peak bone mass is reduced and the risk of osteoporosis is increased. Peak bone mass is also reduced by late menarche. Premature menopause, especially before the age of 45 , is a strong determinant of bone loss and increased risk of fracture among women.

\section{Other causes}

Other causes of osteoporosis are:

- Endocrine disorders-for example, hypogonadism, hyperparathyroidism, Cushing's syndrome.

- Malignant disease-for example, myeloma, lymphoma.

- Drugs-for example, corticosteroids, heparin.

- Miscellaneous disorders-for example, connective tissue diseases, chronic renal failure.

\section{Genetic factors}

Studies in twins reveal that around $50 \%$ of the variance in peak bone mass is genetically determined. The hereditability is believed to be polygenic. In addition, genetic effects appear to be stronger in the lumbar spine than in the femoral neck or distal forearm.

\section{INVESTIGATIONS FOR THE DIAGNOSIS OF OSTEOPOROSIS}

In women, bone loss begins at or shortly before the menopause in the spine and as early as the mid-30s in the femoral neck. Bone mass is a major determinant of bone strength. Moreover, prospective studies have shown an increasing gradient of risk of fracture with decreasing bone density. ${ }^{22}$ Several methods are available for the assessment of bone mass. The method that is most widely used is the DXA scan. It has the ability to assess bone mass at both axial and appendicular sites, has high reproducibility, and the doses of radiation used are very low. ${ }^{23}$

Quantitative computed tomography enables measurement of cortical and cancellous bone in the spine or the peripheral skeleton. The disadvantages are that the equipment is expensive and the radiation dose is relatively high. The other available method is broadband ultrasonic velocity and attenuation of the os calcis, tibia, or patella. It is radiation-free, portable, and relatively cheap. However, it is unable to diagnose osteoporosis as defined by the World Health Organisation and has poor reproducibility. It still remains a research tool.

The absolute BMD for a given bone mass varies with different systems. ${ }^{24}$ Moreover, there are differences in the reference data provided by the manufacturer so that the same measured value may lie within different parts of the reference range depending on the system used. ${ }^{25}$ The presence of extraskeletal
- In the UK it is estimated that 902 DXA scans per 100000 population would be required each year.

- The cost for an average health district of 300000 people would be $£ 129888$ per year.

calcification, osteophytes, scoliosis and vertebral deformity, especially in elderly patients may affect the measurement of $\mathrm{BMD}^{26}$

\section{Clinical indications for bone densitometry}

At present population based screening using DXA cannot be justified. Patients should be measured only if there are strong clinical risk factors and if the result will influence the management of the patient. Strong risk factors include premature menopause ( $<45$ years), prolonged secondary amenorrhoea, and prolonged treatment with corticosteroids ( $>7.5 \mathrm{mg}$ /day for six months or more). Moreover, bone densitometry should be used in patients with radiological evidence of osteopenia or vertebral deformity and those with a history of fragility fracture at the wrist, hip, or spine. Finally, bone densitometry should be used in the monitoring of therapy of osteoporosis-for example, patients on bisphosphonates.

In the spine and forearm effects of treatment can usually be detected within two years but in the femur three or more years may be required. ${ }^{27}$

\section{Implications for the NHS}

In the UK it is estimated that 902 DXA scans per 100000 population would be required each year (based on the national survey of DXA scan provision and epidemiological needs assessment). One hundred and forty seven would be for men and women with previous low trauma fracture, 194 for patients with radiographic evidence of osteopenia, 215 for patients on long term corticosteroids ( $>7.5 \mathrm{mg}$ prednisolone daily for six months or more), 107 for patients with family history of osteoporosis, 107 for patients with other clinical risk factors (such as height loss, kyphosis, low body mass index, that is $\left.<19 \mathrm{~kg} / \mathrm{m}^{2}\right)$, and 78 for women with oestrogen deficiency (menopause or hysterectomy $<45$ years, secondary amenorrhoea greater than six months not due to pregnancy, primary hypogonadism). Therefore, in an average health district of 300000 people with the age and sex structure of the population of the UK facilities would be required to scan 2706 men and women. On average DXA scans cost $£ 48$ for the lumbar spine and femoral neck and provision of such a service for a population of 300000 would require $£ 129888$ per year.

\section{PREVENTION AND TREATMENT OF OSTEOPOROSIS}

The aim of prevention and treatment is to prevent the occurrence of future fractures. Lifestyle changes that might help to diminish the frequency of osteoporosis and fractures should be encouraged. These include improving nutrition (that is, adequate calcium and vitamin D intake), maximising physical activity, reducing smoking, and avoiding heavy alcohol consumption. Moreover, attempts should be made to reduce the risk of falling for elderly people. Measures such as avoidance of loose rugs, improvement in lighting, correction of deficits in vision and hearing, avoidance of sedative drugs, and hip protectors among compliant nursing home residents will all help.

Moreover, treatment of the patient with osteoporosis requires supportive therapy, including analgesia, physiotherapy, hydrotherapy, and appropriate orthopaedic management in those with fracture of the hip, the radius or other long bones.

In patients with risk factors for osteoporosis and in those with previous fragility fractures the BMD should be measured, ideally by DXA scan. If the T score is normal-that is, above 


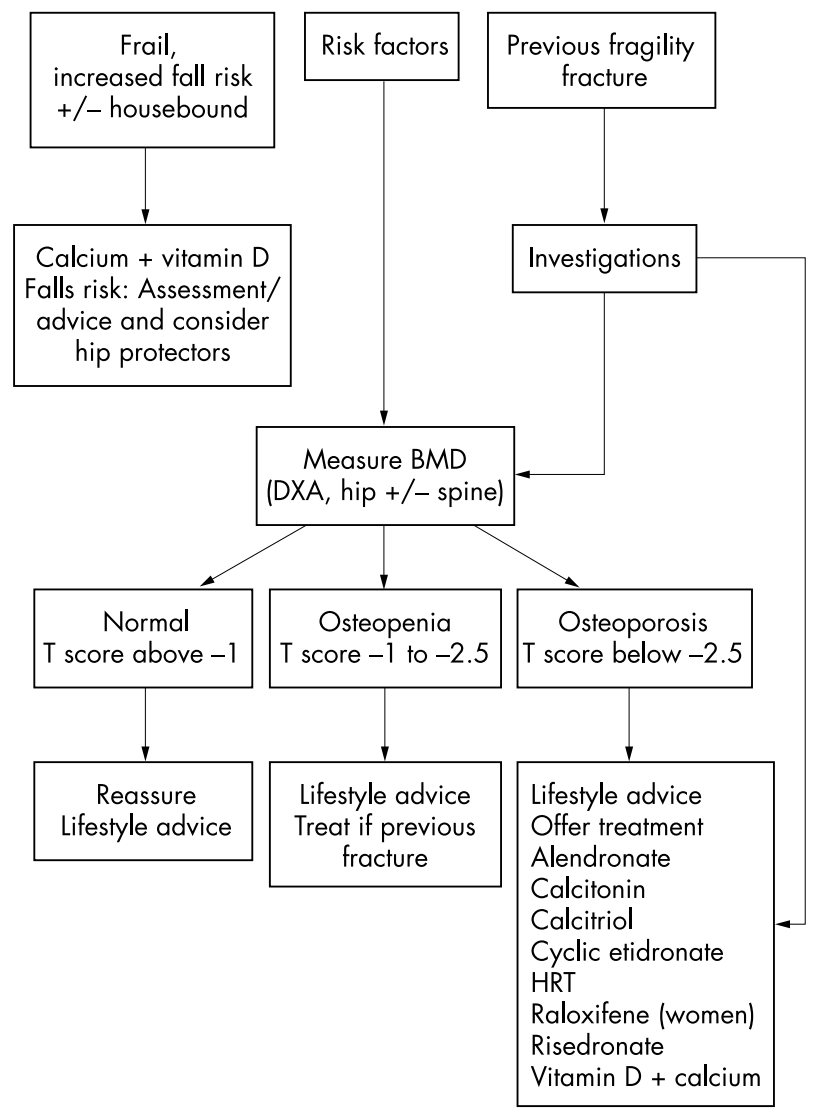

Figure 2 Management algorithm for men and women aged over 45 years who have or are at risk of osteoporosis (BMD, bone mineral density; DXA, dual energy $x$-ray absorptiometry; HRT, hormone replacement therapy). Derived from the Royal College of Physicians' Guidelines. ${ }^{28}$

-l-then the patient should be reassured and lifestyle advice provided. If the $\mathrm{T}$ score is in the osteopenic range-that is, from -1 to -2.5 - then treatment should be offered if there has been a previous fracture. Otherwise, lifestyle advice should be provided and the DXA scan should be repeated after 12-18 months. If the BMD is in the osteoporotic range-that is, the $\mathrm{T}$ score is below -2.5-then treatment should be started and lifestyle advice provided (fig 2 ). ${ }^{28}$

\section{Pharmacological treatments}

Bisphosphonates are synthetic analogues of inorganic pyrophosphate that inhibit bone resorption. Regimens include cyclical etidronate/calcium, risedronate, and alendronate. Cyclical etidronate/calcium is given as $400 \mathrm{mg}$ of etidronate daily for 14 days followed by a calcium supplement of $500 \mathrm{mg}$ daily for 76 days. Alendronate is given as a daily dose of $10 \mathrm{mg}$ or $70 \mathrm{mg}$ once weekly and risedronate as a daily dose of $5 \mathrm{mg}$. Calcium supplements are not included in the formulation but are advised in women with a low dietary calcium intake. The evidence for the antifracture efficacy of alendronate and risedronate appears to be better for non-vertebral and hip fractures compared with cyclical etidronate. ${ }^{28}$ On the other hand, there is good evidence for the antifracture efficacy of alendronate, risedronate, and cyclical etidronate for spinal fractures.$^{28}$ Number-needed-to-treat calculations suggest that 40 or fewer women with prevalent vertebral fractures and osteoporosis need treatment with alendronate or risedronate to prevent either a vertebral or non-vertebral fracture. In women with a low BMD, but no prevalent fractures, more women require treatment to prevent a fracture because fracture rates are much lower in this group. ${ }^{29}$
Oestrogens can prevent bone loss around the menopause. Epidemiological studies suggest that oestrogens can prevent fractures of the radius, hip, and vertebrae. ${ }^{30}$ When oestrogens are combined with progestagens the risk for endometrial cancer is not increased. However, bone loss restarts when oestrogen therapy is discontinued and the positive effects of therapy disappear in the following years. Therefore, oestrogen therapy should be prescribed for at least eight or 10 years, but the longer the use the greater the risk of breast cancer. ${ }^{31}$ It has been shown that good compliance with hormone replacement therapy (HRT) long term is achievable..$^{32}$ The bone sparing dose of oestradiol is $2 \mathrm{mg}$ daily, while that of conjugated equine oestrogen is $0.625 \mathrm{mg}$ daily. The risks and benefits of HRT should be discussed with each individual patient. Testosterone can be considered in hypogonadal men.

Raloxifene is a non-steroidal benzothiophene. It has been classified as a selective oestrogen receptor modulator and it inhibits bone resorption. In a long term, placebo controlled, double blind study raloxifene at doses of 30, 60, and $150 \mathrm{mg}$ per day was shown to significantly increase the BMD of the lumbar spine, hip and total body, whereas those receiving placebo had decreases in BMD. ${ }^{33}$ The MORE (Multiple Outcomes of Raloxifene Evaluation) trial revealed that raloxifene at doses of 60 and $120 \mathrm{mg}$ per day significantly reduced the risk of new vertebral fracture in women with and without previous history of fracture compared with placebo. Moreover, all treatment arms experienced a significant increase in BMD compared with placebo. ${ }^{34}$ In addition, unlike oestrogen, raloxifene does not appear to stimulate endometrial hyperplasia or increase the risk of breast cancer in postmenopausal women.

Calcitonin is a naturally occurring hormone, which inhibits bone resorption, decreases osteoclast formation and osteoclast attachment. In a randomised trial of nasal spray salmon calcitonin in postmenopausal women with established osteoporosis, a dose of 200 IU daily significantly reduced the risk of new vertebral fractures and the lumbar spine BMD increased significantly..$^{35}$ In some patients with vertebral fractures calcitonin provides effective pain relief.

Intermittent parathyroid hormone injection restores bone strength by stimulation of new bone formation, thickening the cortices and existing trabeculae of the skeleton, and perhaps increasing trabecular numbers and their connectivity. ${ }^{36}$ It has been shown in a double blind, placebo controlled prospective study involving 1637 postmenopausal women with previous vertebral fractures that daily treatment with subcutaneous 1-34 fragment recombinant human parathyroid hormone $20 \mu \mathrm{g}$ or $40 \mu \mathrm{g}$ greatly reduced the incidence of new vertebral fractures (relative risk 0.35 and 0.31 respectively). The median treatment period was 19 months. The incidence of non-vertebral fragility fractures was reduced by $53 \%$ for both doses. There were significant increases of the BMD at the spine and the femoral neck. High dose parathyroid hormone occasionally caused nausea and vomiting. There was a dose dependent rise in serum calcium within 4-6 hours after injection that was mild and transient, occurring in $11 \%$ of patients who received parathyroid hormone $20 \mu \mathrm{g} .{ }^{37}$ Parathyroid hormone $20 \mu \mathrm{g}$ per day has been submitted for approval for treatment of osteoporosis in the USA and Europe.

Calcium supplements should be given as an adjunct to other treatments. Calcium supplementation has a positive effect on BMD before the menopause and several years after the menopause but not in the perimenopausal period..$^{38}{ }^{39}$ Moreover, there is some evidence that calcium may prevent vertebral fractures. ${ }^{40}$ Vitamin D supplementation corrects vitamin D deficiency, suppresses secondary hyperparathyroidism, and increases BMD in the femoral neck. ${ }^{41}$ In a study in France, supplementation with vitamin D3 800 IU/day and calcium $1200 \mathrm{mg} /$ day decreased the incidence of hip fractures and other peripheral fractures in nursing home residents who were vitamin D deficient and had a low calcium intake. ${ }^{42}$ 


\section{Box 2: Treatment}

- No more than $14 \%$ of patients taking continuous oral glucocorticoids receive treatment to prevent bone loss.

- Treatment should be considered for adults who will receive glucocorticoids at doses of $7.5 \mathrm{mg} /$ day or more for six months or more.

- In the UK the most commonly used therapies are the bisphosphonates and HRT.

\section{Box 3: Key references}

- Black D, Cooper C. Epidemiology of fractures and assessment of fracture risk. Clin Lab Med 2000;20:439-53.

- Cummings SR, Nevitt MC, Browner WS, et al. Risk factors for hip fracture in white women. N Engl J Med 1995:332:767-73.

- Compston JE, Cooper C, Kanis JA. Bone densitometry in clinical practice. BM 1995;310:1507-10.

- Compston J. Prevention and treatment of osteoporosis. Clinical guidelines and new evidence. J R Coll Physicians Lond 2000;34:518-21.

- Eastell R, Reid DM, Compston J, et al. A UK consensus group on management of glucocorticoid-induced osteoporosis: an update. J Intern Med 1998;244:271-92.

Calcitriol is the active metabolite of vitamin D. A daily dose of $0.25 \mu \mathrm{g}$ twice daily may reduce the rate of new vertebral fractures in women with postmenopausal osteoporosis. ${ }^{43}$ Potential adverse effects include hypercalcaemia and hypercalciuria and therefore plasma calcium should be monitored regularly.

\section{Management of glucocorticoid induced osteoporosis}

In the UK, more than 250000 patients take continuous oral glucocorticoids. However, no more than $14 \%$ receive treatment to prevent bone loss, which is a major complication.$^{44}$ Bone loss is highest in the initial months of treatment and between 30\% and $50 \%$ of patients taking long term corticosteroids will experience fractures. ${ }^{45}$ Corticosteroid induced bone loss appears to be due to a combination of increased bone resorption and decreased bone formation caused by several mechanisms. Corticosteroids decrease the level of sex steroids, reduce the number and activity of osteoblasts, decrease intestinal calcium absorption, increase the resorption activity of osteoclasts, increase urinary calcium excretion, and increase bone cellular responsiveness to parathyroid hormone. ${ }^{46}$

Treatment should be considered for adults who will receive glucocorticoids at doses of $7.5 \mathrm{mg} /$ day or more for six months or more. Lifestyle advice should be provided as discussed earlier. The glucocorticoid doses should be kept to the minimum necessary for disease control and alternative routes of administration such as inhaled glucocorticoids (which have less effect on bone than oral preparations) should be considered where possible-for example, for patients with asthma. Moreover, alternative glucocorticoids such as deflazacort and budesonide, which are thought to have less effect on bone, should be considered where possible.

Pharmacological measures that can be considered in both the primary and secondary prevention of glucocorticoid induced osteoporosis and treatment include the bisphosphonates, HRT, calcitriol, calcitonin, and vitamin D and calcium. In the UK the most commonly used therapies are the bisphosphonates and HRT. ${ }^{44}$

\section{Authors' affiliations}

C Christodoulou, C Cooper, MRC Environmental Epidemiology Unit, University of Southampton, Southampton General Hospital, Southampton
Box 4: Questions (true (T)/false (F); answers at end of paper)

1. The frequency of osteoporosis in women aged 80 years or more is less than $50 \%$.

2. There are significant differences in the incidence and impact of osteoporosis in different populations around the world

3. The financial and health related costs of osteoporosis will rise in future generations

4. The mortality rate in an elderly person with hip fracture approaches $20 \%$.

5. Physical loading and mechanical stress decrease bone mineral density.

6. Broadband ultrasonic velocity and attenuation of the os calcis, tibia, or patella can be used to diagnose osteoporosis as defined by the World Health Organisation.

7. At present population based screening using dual energy $x$-ray absorptiometry (DXA) cannot be justified.

8. In the UK it is estimated that 2000 DXA scans per 100000 population would be required each year.

9. The evidence for the antifracture efficacy of alendronate and risedronate appears to be better for non-vertebral and hip fractures compared with cyclical etidronate.

10. Most patients taking long term corticosteroids receive treatment to prevent bone loss.

\section{REFERENCES}

1 Consensus Development Conference. Prophylaxis and treatment of osteoporosis. Osteoporosis Int 1991;1:114-7.

2 Royal College of Physicians. Osteoporosis: clinical guidelines for prevention and treatment. London: Royal College of Physicians of London, 1999.

3 Eddy D, Johnston C, Cummings SR, et al. Osteoporosis: review of the evidence for prevention, diagnosis, and treatment and cost-effectiveness analysis. Osteoporosis Int 1998;8(suppl 4):S1-80.

4 Black D, Cooper C. Epidemiology of fractures and assessment of fracture risk. Clin Lab Med 2000;20:439-53.

5 Kanis JA and the WHO Study Group. Assessment of fracture risk and its application to screening for postmenopausal osteoporosis: a synopsis of the WHO report. Osteoporosis Int 1994;4:368-81.

6 Melton LJ, Chrischilles EA, Cooper C, et al. Perspective. How may women have osteoporosis? J Bone Miner Res 1992;7: 1005-10.

7 Cooper C. Epidemiology and public health impact of osteoporosis. Clin Rheumatol 1993;7:459-77.

8 Looker AC, Orwoll ES, Johnston CC, et al. Prevalence of low femoral bone density in older US adults. From NHANES III. J Bone Miner Res 1997:12:1761-8

9 Cooper C, Melton L. Magnitude and impact of osteoporosis and fractures. In: Marcus R, Feldman D, Kelsey J, eds. Osteoporosis. San Diego: Academic Press, 1996: 419-34.

10 Johnell O, Gullberg B, Allander E, et al. The apparent incidence of hip fracture in Europe: a study of national register sources. Osteoporosis Int $1992 \cdot 2 \cdot 298-302$

11 Royal College of Physicians of London. Fractured neck of femur: prevention and management. London: Royal College of Physicians, 1989.

12 Cooper C, Atkinson EJ, Jacobsen JJ, et al. Population-based study of survival after osteoporotic fractures. Am J Epidemiol 1993;137:1001-5.

13 Browner WS, Sealey DG, Vogt TM, et al. Non-trauma mortality in elderly women with low bone mineral density. Lancet 1991;338:355-8.

14 Chrischilles EA, Butler CD, Davis CS, et al. A model of lifetime osteoporosis impact. Arch Intern Med 1991;151:2026-32.

15 Office of Technology Assessment, Congress of the United States. Hip fracture outcomes in people age 50 and over: mortality, service use, expenditures and long-term functional impairment. Washington, DC: US Department of Commerce Publication, 1993 (NTIS PB 94 107653).

16 Gold DT. The clinical impact of vertebral fractures: quality of life in women with osteoporosis. Bone 1996;18(suppl 3):S185-9

17 Law MR, Hackshaw AK. A meta-analysis of cigarette smoking, bone mineral density and risk of hip fracture: recognition of a major effect. BM 1997:315:841-6.

18 Cummings SR, Nevitt MC, Browner WS, et al. Risk factors for hip fracture in white women. N Engl J Med 1995:332:767-73.

19 Seeman E. The effects of tobacco and alcohol use on bone. In: Marcus R, Feldman D, Kelsey J, eds. Osteoporosis. San Diego: Academic Press, 1996: 577-97

20 Cumming RG, Nevitt MC. Calcium for prevention of osteoporotic fractures in post- menopausal women. J Bone Miner Res 1997:12:1321-9.

21 Snow CM, Shaw JM, Matkin CC. Physical activity and risk of osteoporosis. In: Marcus R, Feldman D, Kelsey J, eds. Osteoporosis. San Diego: Academic Press, 1996: $511-28$. 
22 Cummings SR, Black DM, Nevitt MC, et al. Bone density at various sites for prediction of hip fractures. Lancet 1993:341:72-5.

23 Mazess RB, Collick B, Tempe J, et al. Performance evaluation of a dual-energy $\mathrm{X}$-ray bone densitometer. Calcif Tissue Int 1989;44:228-32.

24 Laskey MA, Flaxman ME, Barber RW, et al. Comparative performance in vitro and in vivo of Lunar DPX and Hologic QDR-1000 dual-energy X-ray absorptiometers. Br J Radiol 1991:64:1023-9.

25 Laskey MA, Crisp AJ, Cole TJ, et al. Comparison of the effect of different reference data on Lunar DPX and Hologic QDR -1000 dual-energy X-ray absorptiometers. Br J Radiol 1992;65:1 124-9.

26 Reid IR, Evans MC, Amer R, et al. The influence of osteophytes and aortic calcification on spinal bone mineral density in postmenopausa women. J Clin Endocrinol Metab 1991;72:1372-4.

27 Compston JE, Cooper C, Kanis JA. Bone densitometry in clinical practice. BM 1995;310:1507-10.

28 Compston J. Prevention and treatment of osteoporosis. Clinical guidelines and new evidence. J R Coll Physicians Lond 2000;34:518-21

29 Hodsman AB, Hanley DA, Josse R. Do bisphosphonates reduce the risk of osteoporotic fractures? An evaluation of the evidence to date. Can Med Assoc J 2002:166:1426-30.

30 Grady D, Rubin SM, Petitti DB, et al. Hormone therapy to prevent disease and prolong life in postmenopausal women. Ann Intern Med 1992;117:1016-37.

31 Colditz GA, Hankinson SE, Hunter DJ, et al. The use of estrogens and progestins and the risk of breast cancer in postmenopausal women. $N$ Engl J Med 1995:332:1589-93.

32 Wu F, Ames R, Clearwater J, et al. Prospective 10-year study of the determinants of bone density and bone loss in normal postmenopausal women, including the effect of hormone replacement therapy. Clin Endocrinol 2002;56:703-11.

33 Delmas PD, Bjarnason NH, Mitlak BH, et al. Effects of raloxifene on bone mineral density, serum cholesterol concentrations, and uterine endometrium in postmenopausal women. N Engl J Med 1997;337:1641-7.

34 Ettinger B, Black D, Mitlak BH, et al. Reduction of vertebral fracture risk in postmenopausal women with osteoporosis treated with raloxifene: results from a 3-year randomised clinical trial. Multiple Outcomes of Raloxifene Evaluation (MORE) Investigators. JAMA 1999;282:637-45.
35 Chesnut $\mathbf{C H}$, Silverman S, Andriano K, et al. A randomized trial of nasal spray salmon calcitonin in postmenopausal women with established osteoporosis: the prevent recurrence of osteoporotic fractures study. PROOF Study Group. Am J Med 2000; 109:267-76.

36 Delmas PD. Treatment of postmenopausal osteoporosis. Lancet 2002;359:2018-26.

37 Neer RM, Arnaud CD, Zanchetta JR, et al. Effect of parathyroid hormone (1-34) on fractures and bone mineral density in postmenopausal women with osteoporosis. N Engl J Med 2001;344:1434-41.

38 Prince RL, Smith M, Dick IM, et al. Prevention of postmenopausal osteoporosis. A comparative study of exercise, calcium supplementation, and hormone-replacement therapy. N Engl J Med 1991;325: 1 189-95.

39 Elders PJ, Lips P, Netelenbos JC, et al. Long-term effect of calcium supplementation on bone loss in perimenopausal women. J Bone Miner Res 1994;9:963-70.

40 Dawson-Hughes B. Calcium, vitamin D and vitamin D metabolites. In: Papapoulos SE, Lips P, Pols HAP, et al, eds. Osteoporosis. 96 International Congress Series 1118 . Amsterdam: Excerpta Medica, 1996: 299-303.

41 Ooms ME, Roos JC, Bezemer PD, et al. Prevention of bone loss by vitamin D supplementation in elderly women: a randomized double-blind trial. I Clin Endocrinol Metab 1995:80:1052-8.

42 Chapuy MC, Arlot ME, Duboeuf F, et al. Vitamin D3 and calcium to prevent hip fractures in the elderly women. N Engl J Med 1992; 327: 1637-42.

43 Tilyard MW, Spears GF, Thomson J, et al. Treatment of postmenopausal osteoporosis with calcitriol or calcium. N Engl J Med 1992;326:357-62.

44 Eastell R, Reid DM, Compston J, et al. A UK Consensus Group on management of glucocorticoid-induced osteoporosis: an update. J Intern Med 1998;244:271-92.

45 Lukert BP, Raisz LG. Glucocorticoid-induced osteoporosis: pathogenesis and management. Ann Intern Med 1990;1 12:352-64.

46 Adachi JD, Roux C, Pitt Pl, et al. A pooled data analysis on the use of intermittent cyclical etidronate therapy for the prevention and treatment of corticosteroid induced bone loss. J Rheumatol 2000;27:2424-31.

\section{ANSWERS}

1. False; 2. true; 3 . true; 4. true; 5 . false; 6 . false; 7. true; 8 . false; 9. true; 10. false.

\section{Preventing cardiogenic shock protects patients with acute MI}

ore patients admitted with acute myocardial infarction (MI) could be saved if cardiogenic shock

M (CS) was prevented, concludes a review.

Early recognition of cardiogenic shock is crucial but tricky, the authors say. Decreased peripheral blood flow despite sufficient blood volume indicates CS, and in the time around infarction sustained hypotension and decreased peripheral blood flow. However, signs can vary. In particular, patients with anterior MI and tissue hypoxia but normal blood pressure should be assumed to have CS. This pre-shock state has a very poor prognosis; if unrecognised and treated with $\beta$ blockers it will precipitate overt CS.

The causes of CS are left ventricular fibrillation - the most common-right ventricular fibrillation, and mechanical failure. In trials early revascularisation significantly improves survival, but only in patients under 75, and this is the treatment strategy endorsed by the ACC/AHA. The immediate priorities are resuscitation and maintaining arterial pressure. Aspirin and full dose heparin should be given. IABP is indicated for patients with ST elevation MI needing angiography and glycoprotein IIb/IIIa inhibitor for non-ST elevated MI.

Then judging the state of the heart and cardiac vessels is the crux of treatment-a task for a tertiary referral centre-and patients should be supported with prophylactic IABP before and during transfer. The classic anatomical picture is of triple vessel disease, left main disease, and decreased left ventricular function.

CS often goes unrecognised, and though it often occurs soon after MI, many patients with ST or non-ST elevation MI die as a result.

\ Heart 2002;88:531-537.

Please visit the Postgraduate Medical Journal website [www. postgradmedj.com] for link to this full article. 